\section{Management of bacterial keratitis: beyond exorcism towards consideration of organism and host factors}

\author{
Eye (2003) 17, 957-974. doi:10.1038/ \\ sj.eye. 6700635
}

Keywords: cornea; bacterial; keratitis; pseudomonas; antibiotics; genomics

\section{Introduction}

Microbial keratitis is a common, potentially sight threatening ocular infection that may be caused by bacteria, fungi, viruses, or parasites. ${ }^{1}$ The challenge for the ophthalmologist is to distinguish clinically microbial keratitis from other noninfectious inflammatory conditions of the cornea resulting from trauma, hypersensitivity, and other immune-mediated reactions. A further challenge is to develop a clinical suspicion for a bacterial keratitis as opposed to the other potential infectious causes.

There are no absolutely specific clinical signs that confirm infection or suggest definite bacterial cause, yet the clinician should assess and define the distinctive corneal signs based on the status of the epithelium (intact or ulcerated), type of stromal inflammation (suppurative or nonsuppurative), and the site of the stromal inflammation (focal, diffuse, multifocal, or marginal). When there is sufficient evidence based on clinical examination to raise the suspicion for a possible infectious etiology, laboratory studies are required to establish the specific causative organism. Based on the clinical setting and risk factors, features of clinical examination, results from laboratory investigation, and knowledge of the potential corneal pathogens, a therapeutic plan is initiated. ${ }^{2}$ Modification of the therapeutic plan is subsequently based on clinical response, results of in vitro susceptibility determination, and tolerance of the antimicrobial agents. ${ }^{3}$ With
TP O'Brien

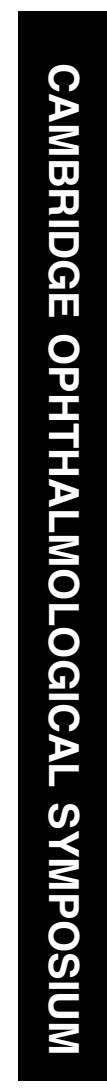

careful clinical monitoring, antimicrobial therapy is then terminated and any residual structural alterations corrected.

Recent trends in therapy of suspected bacterial keratitis have evolved towards an 'exorcist approach'. Potent, preferably bactericidal, antibacterial agents are poured onto the ocular surface at frequent intervals, sometimes without the benefit of antecedent diagnostic studies, in an effort to exorcise the invading pathogen(s). Research into ever more potent compounds has steadily progressed, in part stimulated by emerging patterns of resistance among pathogens, resulting in development of powerful newer commercial antibacterial agents that reinforce the 'exorcist approach'. Relatively little attention, however, has been directed towards strategies for preventing destruction of the corneal tissue as a result of release of organism- and host-derived factors. Newer approaches to gain better understanding of the molecular microbiologic events involved in the infectious process will allow development of a comprehensive treatment strategy focused on not only the organism but important host factors as well. Tools for the new frontier in therapy of infectious keratitis will likely emerge from microbial genomics and proteomics. Such tools will hopefully identify newer targets for intervention to prevent corneal destruction as a result of infectious keratitis.

Contemporary strategies for management of suspected acute bacterial keratitis must include consideration of organism- and host-derived factors in order to maximize eradication of the invading pathogen(s) while simultaneously protecting the orderly corneal anatomy in order to preserve function.
Ocular Infectious Diseases Ocular Microbiology Laboratory The Wilmer Ophthalmological Institute The Johns Hopkins University School of

Correspondence: TP O'Brien Ocular Infectious Diseases Ocular Microbiology Laboratory The Wilmer Ophthalmological Institute The Johns Hopkins University School of Medicine

Baltimore, MD, USA

Tel: + 14109551671

Fax: + 14106140682

E-mail: tobrien@

jhmi.edu

${ }^{1}$ Presented at the $32 \mathrm{nd}$

Cambridge

Ophthalmological

Symposium, The Cornea, 4-6 September 2002

Received: 28 February 2003 Accepted in revised form: 28 February 2003 


\section{Pathogenesis}

The pathogenesis of ocular infectious disease is determined by the intrinsic virulence of the microorganism, the nature of the host response, and the anatomical features of the site of the infection. ${ }^{4}$ The avascular clear anatomical structure of the cornea with its specialized microenvironment predisposes to potential alteration and destruction by invading microorganisms, virulence factors, and host response factors. The intrinsic virulence of organism relates to its ability to invade tissue, resist host defense mechanisms, and produce tissue damage. ${ }^{5}$ Penetration of exogenous bacteria into the corneal epithelium typically requires a defect in the surface of the squamous epithelial layer. By virtue of specialized enzymes and virulence factors, a few bacteria, such as Neisseria gonorrhea, N. meningitidis, Corynebacterium diphtheriae, Shigella and Listeria may directly penetrate corneal epithelium to initiate stromal suppuration.

Bacteria colonize host cells by engaging adhesins at their surface with receptors on the host cell surface. Specific receptors are often required by many adhesins to achieve binding. Besides adherence, microbial adhesins also contribute to subsequent interactions. Virulence factors may initiate microbial invasion or secondary effector molecules may assist the infective process. Upregulation or downregulation of host defense mechanisms may be involved. Adhesins may also be toxins. ${ }^{6}$ Therefore, receptor recognition is only the first step in the pathogenesis of infection directed by microbial adhesin molecules. ${ }^{7}$

Many bacteria display several adhesins on fimbriae (pili) and nonfimbriae structures. Such adhesive proteins may recognize carbohydrates on host cells, or alternatively protein-protein interactions can also occur.

Certain bacteria exhibit differential adherence to corneal epithelium. The adherence of Staphylococcus aureus, S. pneumoniae, and Pseudomonas aeruginosa to ulcerated corneal epithelium is significantly higher than other bacteria and may account in part for their frequent isolation. ${ }^{8}$

$P$. aeruginosa has many virulence factors that contribute to pathogenesis. Cell-associated structures such as pili ${ }^{9}$ and flagella ${ }^{10}$ and extracellular products, such as alkaline protease, ${ }^{11}$ elastase, ${ }^{11}$ exoenzyme $S,{ }^{6}$ exotoxin $A,{ }^{12}$ endotoxin, ${ }^{13}$ slime polysaccharide ${ }_{,}^{14}$ phospholipase $C_{,}{ }^{11}$ and leukocidin, ${ }^{11}$ are associated with virulence, invasiveness, and colonization. Whereas Gram-positive bacteria, including $S$. aureus, adhere to host tissues via fibronectin and collagen, ${ }^{15}$ P. aeruginosa attaches to cell surfaces that lack fibronectin. ${ }^{16}$ Bacteria adhere to injured cornea, ${ }^{17}$ to exposed corneal stroma, ${ }^{18}$ or to immature nonwounded cornea. ${ }^{19}$ The corneal epithelial receptors for Pseudomonas spp are glycoproteins. ${ }^{20,21}$

Pili (fimbriae) are thin (4-10 $\mathrm{nm}$ in diameter) protein filaments, which are located on the surfaces of many bacteria. In vitro studies indicate that purified pili successfully compete for binding with cold bacteria by saturating available binding sites on the ocular surface. ${ }^{22}$ Monoclonal antibodies specific for Pseudomonas pili and a peptide-conjugated alkaline phosphatase allowed for identification of host corneal receptor molecules. ${ }^{23}$ Characterization of these receptor proteins indicates that carbohydrates are necessary for receptor activity. ${ }^{21}$ In competitive inhibition experiments, sialic acid was the only aminosugar able to completely inhibit pilus binding to mouse corneal epithelial proteins. Pili have been used to protect against $P$. aeruginosa keratitis. ${ }^{22}$ Pili, however, have considerable antigenic variation between strains. ${ }^{24}$ Bacteria also possess an array of other virulence factors, including nonpilus adhesins. ${ }^{25}$ Some clinical isolates of $P$. aeruginosa from keratitis are reportedly nonpiliated. ${ }^{26}$

Flagella are subcellular filamentous organelles (16$18 \mathrm{~nm}$ in diameter) originating in the cell membrane and extending to $15-20 \mu \mathrm{m}$ from its surface. These organelles are responsible for bacterial motility, which is important for dissemination of infection. ${ }^{27}$ The flagellum has a helicofilament composed of cell-assembling subunits of the protein flagellin. More than $95 \%$ of $P$. aeruginosa clinical isolates are flagellated. ${ }^{28}$ As flagella contain aminospecific proteins and have large surface exposure available for antibody binding, they have been considered as the basis for vaccine development. Much research examining flagellum as a virulence factor in $P$. aeruginosa infection and/or as a vaccine candidate has focused on the burned-mouse model. ${ }^{29}$ A loss of virulence was observed in flagella-deficient mutants. Active or passive systemic, as well as topical immunization with flagella, or topical antiflagellar antibody homologous to the infecting strain of bacteria, protects mice against $P$. aeruginosa corneal infection. ${ }^{30}$

In addition to adhesins, the adherence of P. aeruginosa and $N$. gonorrheae is guided by glycocalyx, a biological slime that enables them to adhere to susceptible cells producing slime aggregates that are resistant to phagocytosis. ${ }^{31}$ Similar coatings may form on contact lenses to facilitate the adherence of bacteria to the lens material. $^{32}$

Following adherence of microorganism to the cornea and initiation of infection, the complex tissue reactions of the host response occur, including inflammation, neovascularization, cellular and humoral immune responses, and stromal degradative processes.

A variety of cytokines may be released in response to corneal infection. During inflammation, leucocyte adhesion to the vascular endothelium is enhanced by 
interleukin-I (IL-I) and tumour necrosis factor (TNF), products of macrophages and T lympocytes. ${ }^{33}$ IL-I is a known potent intracellular mediator of inflammation and chemotaxis for neutrophils. TNF stimulates immunocompetent cells and induces release of IL-I and interleukin-VI (IL-VI) from macrophages and other cells. ${ }^{34}$ Bacterial exotoxin-A downregulates TNF, IL-I, and lymphotoxin by inhibiting the cells' ability to produce these cytokines. ${ }^{35}$

Neutrophil infiltration following corneal infection is a principal host defense mechanism. The host inflammatory response to Pseudomonas spp has been studied in mice designated as susceptible or resistant. Susceptible mice are unable to clear the cornea, whereas resistant mice may restore corneal clarity within 1 month after ocular challenge. ${ }^{36}$ Resistant mice appear to have a larger number of corneal leucocytes present initially. The resistant mice also have a shorter duration of inflammatory cells and bacteria in the cornea compared with susceptible mice.

If neutrophils are experimentally depleted, many resistant animals succumb to lethal Pseudomonas sepsis within $48 \mathrm{~h} \cdot{ }^{37}$ In aged mice, deficiencies of neutrophilic phagocytosis have been observed. These observations may partially explain the clinically apparent age-related susceptibility of individuals to corneal infection.

Preimmunization of rats with phenol-killed Pseudomonas organisms still results in massive corneal stromal degradation caused by neutrophil migration in the absence of viable bacteria. Naive, unimmunized mice show little stromal destruction during early infection, despite the presence of numerous bacteria in the cornea. Thus, immune recognition is involved in the host response to Pseudomonas corneal infection and is apparently required for phagocytosis, but not for neutrophil recruitment. ${ }^{38}$

Models of experimental P. aeruginosa ocular disease also indicate the importance of the third component of complement (C3) in host resistance to corneal infection. Resistant mice, experimentally depleted of C3 by Cobra venom and then inoculated with Pseudomonas organisms to the cornea, respond with delayed leucocyte mobility, bacterial persistence in the cornea, and subsequent scarring and opacification. ${ }^{39}$

The cellular/cytokine network in response to experimental infection in vivo has begun to be unravelled, and the data provide substantive evidence for a regulatory role of CD4 ++ T cells (Th1 type) contributing directly to persistence of PMN in the cornea of susceptible C57BL/6 (cornea perforates) vs resistant $\mathrm{BALB} / \mathrm{c}$ (cornea heals) mice. Additionally, in the susceptible mouse model, CD4(+) T cells interact with Langerhans cells (LC) and B7/CD28 ligation appears critical for antigen presentation and the susceptibility response. Various cytokines and chemokines (eg, MIP1alpha, IL-1beta, MIP-2, IL-12, and IFN-gamma) and their pattern of sustained upregulation after infection in susceptible vs resistant mice also are being understood in the light of an in vivo cytokine network. T-cell-mediated pathogenic mechanisms are of importance in development of the susceptible response to $P$. aeruginosa ocular infection. In the absence of T-cell infiltration into the cornea, PMNs do not persist in the stroma, and cytokines and chemokines are better balanced, resulting in decreased stromal destruction and the resistance response. $^{40}$

Previous experimental studies have shown that extended-wear contact lens usage results in a centripetal migration of LC from the conjunctiva into the central cornea. To test the consequences of this, LC were induced into the cornea before P. aeruginosa infection in BALB/c mice that are normally resistant (the cornea heals) and in C57BL/ 6 mice that are susceptible (the cornea perforates) to bacterial challenge. Mean clinical scores, slit-lamp examination, adenosine diphosphatase (ADPase), and acid phosphatase staining as well as immunostaining with DEC-205, B7-1, CD4, and interleukin-2 receptor (IL$2 \mathrm{R}$ ) antibodies and histopathologic, reverse transcriptionpolymerase chain reaction (RT-PCR), and delayed-type hypersensitivity (DTH) analyses were used to examine the effects on bacterial disease after polystyrene bead induction of LC into the cornea before bacterial challenge. No difference in disease response was observed in bead- $v$ s sham-treated C57BL/ 6 mice after bacterial infection; however, significant differences leading to corneal perforation were seen in BALB/c mice that included an increased number of LC in the central cornea at 1 and 6 days after infection, an increased number of B7-1 + (mature) LC at 6 days after infection, $\mathrm{CD} 4+$ and IL-2R $+\mathrm{T}$ cells at 5 days after infection, enhanced DTH, and increased mRNA levels for IFNgamma in cornea and cervical lymph nodes. Alternately, levels of IL-4 were significantly higher in the cornea and cervical lymph nodes of sham- $v$ s bead-treated animals. These data provide evidence that LC are critical in the innate immune response to $P$. aeruginosa and provide new information regarding the mechanisms governing resistance $v s$ susceptibility to bacterial infection with this opportunistic pathogen. ${ }^{41}$

The role of macrophage inflammatory protein-1alpha (MIP-1alpha) in cell infiltration into P. aeruginosa-infected cornea and subsequent disease was examined. Greater amounts of the chemokine (protein and mRNA) were found in the infected cornea of susceptible B6 ('cornea perforates') vs resistant BALB/c ('cornea heals') mice from 1 to 5 days postinfection. Treatment of BALB/c mice with recombinant (r) MIP-1alpha exacerbated disease and was associated with an increased number of 
neutrophils (PMNs) in the cornea. Treatment of BALB/c mice with rMIP-1alpha also induced recruitment of activated CD $4+\mathrm{T}$ cells into the affected cornea, converting resistant to susceptible mice. Depleting $\mathrm{CD} 4+\mathrm{T}$ cells in $\mathrm{r}$-treated BALB/c mice significantly decreased PMNs in cornea tissue, suggesting that $\mathrm{T}$ cells regulate persistence of PMNs at this site. In B6 mice, administration of neutralizing MIP-1alpha polyclonal antibody also significantly reduced PMN numbers and pathology. Collectively, evidence is provided that MIP1alpha directly contributed to CD4 + T-cell recruitment and indirectly to PMN persistence in the infected cornea. ${ }^{42}$

Macrophage migration inhibitory factor (MIF) is a recently rediscovered proinflammatory cytokine, and has been shown to play a role in the regulation of neutrophil chemokines and angiogenesis. Corneal epithelial and endothelial cells have been shown to express MIF. A study evaluated the expression of MIF during

Pseudomonas keratitis in mice and in vitro using a corneal epithelial cell line. ${ }^{43}$ Three strains of $P$. aeruginosa, 6294 (invasive strain), 6206 (cytotoxic strain), and Paer1 (noninfectious strain), were used. Both cytotoxic and invasive strains were isolated from human corneal ulcers and the Paer1 strain was isolated from a noninfectious condition. Following challenge in mouse corneas or a corneal epithelial cell line, corneal homogenates or lysed corneal epithelial cells were used to isolate RNA. MIF mRNA expression in the mouse cornea or human corneal epithelial cells was examined by RT-PCR analysis, and was found to be expressed as early as $4 \mathrm{~h}$ after the injury (scratch controls) or infection in the mouse corneas. MIF mRNA in scratch controls and Paer1-inoculated corneas showed peak levels at $4 \mathrm{~h}$ postchallenge and this dropped by $24 \mathrm{~h}$ postchallenge. Corneas challenged with invasive and cytotoxic strains showed peak $24 \mathrm{~h}$ postchallenge. MIF mRNA levels were significantly higher in invasive and cytotoxic strain inoculated corneas compared to Paer1-inoculated corneas. Challenging the corneal epithelial cell line with Pseudomonas 6294 and 6206 strains induced peak expression at $8 \mathrm{~h}$ and levels were decreased by $12 \mathrm{~h}$. Epithelial cells inoculated with recombinant human interleukin-1beta protein induced very high levels of MIF mRNA at all time points compared to infected and control corneal epithelial cells. High expression of MIF in the infected corneas suggests that it may have a role in the pathogenesis of corneal disease induced by invasive and cytotoxic strains of P. aeruginosa. ${ }^{43}$

Evidence suggests that $P$. aeruginosa stromal keratitis and corneal perforation (susceptibility) is a CD4(+) T-cell-regulated inflammatory response following experimental $P$. aeruginosa infection. A study examined the role of $\mathrm{LC}$ and the $\mathrm{B} 7 / \mathrm{CD} 28$ costimulatory pathway in P. aeruginosa-infected cornea and the contribution of costimulatory signaling by this pathway to disease pathology. ${ }^{44}$ After bacterial challenge, the number of LC infiltrating the central cornea was compared in susceptible C57BL/6 (B6) vs resistant (cornea heals) $\mathrm{BALB} / \mathrm{c}$ mice. LC were more numerous at 1 and 6 days postinfection, but were similar at 4 days postinfection, in susceptible $v$ s resistant mice. Mature, B7-positive-stained LC in the cornea and P. aeruginosa-associated LC in draining cervical lymph nodes were also increased significantly following infection in susceptible mice. To test the relevance of these data, B6 mice were treated systemically and subconjunctivally with neutralizing B7 (B7-1/B7-2) mAbs. Treatment decreased corneal disease severity and reduced significantly the number of B7positive cells as well as the recruitment and activation of CD4 (+) T cells in the cornea. IFN-gamma mRNA levels were also decreased significantly in the cornea and in draining cervical lymph nodes of $\mathrm{mAb}$-treated mice. When CD28(-/-) animals were tested, they exhibited a less severe disease response (no corneal perforation) than wild-type B6 mice and had a significantly lower delayedtype hypersensitivity response to heat-killed $P$. aeruginosa. These results support a critical role for B7/ CD28 costimulation in susceptibility to $P$. aeruginosa ocular infection. ${ }^{44}$

In $P$. aeruginosa ocular infection, T-helper cell 1-responsive mouse strains are susceptible (the cornea perforates), and neutralization of IFN-gamma before infection has been shown to delay the onset of perforation. IFN-gamma is the predominant cytokine induced by IL-12, and positive regulation of IL-12 by IFN-gamma, if unchecked, leads to excessive cytokine production and toxicity. Despite its potential importance, the role of IL-12 in ocular infection with P. aeruginosa remains unexplored and was the purpose of this study. IL-12 knockout mice, histopathology, RT/PCR and ELISA analyses, immunocytochemistry, and quantitation of viable bacteria in cornea were used to examine the role of IL-12 in IFN-gamma production and the susceptibility phenotype. To test directly the effect of IL-12 on IFNgamma production, IL-12 knockout and wild-type C57BL/6 mice were used. Both groups of mice were susceptible to infection, with corneal perforation seen at 5-7 days after infection. RT-PCR and ELISA analyses confirmed that IL-12 message and protein levels were elevated after infection only in the wild-type mouse cornea. Other differences between the two groups were detected. Knockout $v s$ wild-type mice showed a significant decrease in IFN-gamma mRNA levels in the cornea and cervical lymph nodes and decreased TNFalpha protein levels in cornea. Corneas of knockout mice also had a significant increase in bacterial load at 5 days after infection when compared with wild-type mice. 
These data provide evidence that IL-12 is important in IFN-gamma production, and in the absence of the cytokine, both IFN-gamma and TNF-alpha levels in cornea are significantly decreased, resulting in unchecked bacterial growth and perforation. ${ }^{45}$

In addition to organism factors, host lysosomal enzymes and oxidative substances produced by neutrophils, keratocytes, and epithelial cells may significantly contribute to the destruction caused by Pseudomonas keratitis. ${ }^{46}$ Two eukaryotic gelatinase species have been characterized, including a type IV collagenase $(72 \mathrm{kDa})$ and a type $\mathrm{V}$ collagenase (90-100 kDa). ${ }^{47}$ Corneal epithelial cells produce predominantly the $92 \mathrm{kDa}$ form of progelatinase, whereas stromal fibroblasts synthesize predominantly the $72 \mathrm{kDa}$ progelatinase. ${ }^{48}$ The progelatinase is cleaved by Pseudomonas elastase to produce the active form. ${ }^{49}$

A variety of bacterial toxins and enzymes may be produced during corneal infection to contribute to destruction of the corneal substance. P. aeruginosa produce many toxic substances capable of causing necrotic central corneal ulceration. Toxin-A inhibits protein synthesis much as diphtheria toxin by catalysing the transfer of the adenosine $5^{\prime}$-diphosphate ribose (ADPR) portion of nicotinamide adenine dinucleotide to mammalian elongation factor II. With Staphylococcal keratitis, alpha-toxin, but not protein $\mathrm{A}$, is a major virulence factor mediating corneal destruction. ${ }^{50}$

In summary, the pathogenesis of bacterial keratitis initially requires the adherence of bacteria to disrupted or normal corneal epithelium. Adhesins are microbial proteins that direct the high-affinity binding to specific cell-surface components. These adhesins are able to promote bacterial entry into the host cell, derange leucocyte migration, activate plasmin, and induce cytokine production. In addition, they may act as toxins directly. Adhesins recognize carbohydrate and protein moieties on the host cell surface. Most bacteria can display a number of adhesins. Although the cognate oligosaccharides for bacterial adhesins are known, the molecules bearing these determinants are not well characterized. Integrins are a family of glycoproteins mediating cell-cell and cell-extracellular matrix recognition. Many bacterial pathogens have co-opted the existing integrin-based system masking ancillary ligand recognition in a form of mimicry. Once the bacterial pathogen has adhered to the corneal epithelial surface, the next step in establishing infection is invasion into the corneal stroma. Bacterial invasion is facilitated by proteinases that degrade basement membrane and extracellular matrix and cause cell lysis. Proteinases may be derived from bacteria, corneal cells, and migrating leucocytes. Corneal matrix metalloproteinases are excreted in an inactive form, but are activated during infection by bacterial proteinase. Corneal proteinase production may also be induced during the course of infection. The invasion of bacteria into the cornea is facilitated by a number of exotoxins, including $P$. aeruginosa phospholipase, heat-stable haemolysin, and exotoxin-A, which leads to stromal necrosis. Once the bacterial invasion into the cornea has ensued, infection is further facilitated by a complex sequence leading to interruption of the host immune response.

Exopolysaccharide formation by both Gram-positive and Gram-negative bacteria results in local immunosuppressive effects. Certain bacteria with capsular polysaccharide also have immunosuppressive properties, including interference with phagocytosis. Proteases degrade complement components, immunoglobulins, and cytokines and may inhibit leucocyte chemotaxis and lymphocyte function. Toxin-A inhibits protein synthesis much as diphtheria toxin by catalysing the transfer of ADPR portion of nicotinamide dinucleotide to mammalian elongation factor-II.

Exoenzyme-S is another ADP-ribosyl transferase that may act as an adhesin and also contribute to dissemination of the organism.

Two specific bacterial proteases, elastase and alkaline protease, cause marked destruction of the cornea when injected intrastromally. ${ }^{51,52}$ Intrastromal injection of purified elastase alone also results in severe corneal damage. Inhibition of elastase activity with 2-mercaptoacetyl-L-phenylalanine-L-leucine ${ }^{53}$ prevents keratolysis. The proteases contribute to the pathogenesis of keratitis by degrading basement membrane, ${ }^{54}$ laminin, proteoglycans, extracellular matrix, ${ }^{55}$ and collagen. ${ }^{56}$ In addition, the bacterial proteases inhibit host defense systems by degrading immunoglobulins, interferon, complement, IL-I, IL-II, and TNF. ${ }^{51}$ Such interference results in decreased neutrophil chemotaxis, T-lymphocyte function, and NK cell function. Mutants deficient for alkaline protease do not establish corneal infection, suggesting that this protease is an important initiating factor. ${ }^{57}$ A bacterial heat-labile phospholipase $\mathrm{C}$ has been shown in antibody/substrate specificity studies to be produced in mouse ocular infections suggesting its role as a potential virulence factor. ${ }^{58}$ Bacterial lipopolysaccharide (LPS) stimulates neutrophil migration and infiltration into the cornea with subsequent corneal scarring and opacification. ${ }^{59}$

Bacterial exotoxins are released by actively replicating organisms and some endotoxins are released only after the death of the organism. These enzymes and toxins have been shown to persist in the cornea for a protracted period and continue to cause stromal destruction after the death of the pathogen. Most of the bacterial exotoxins are thermal labile and have antigenic properties.

Gram-positive bacteria elaborate a variety of biologically 
active and immunologically distinct toxins. Coagulasepositive strains of Staphylococci are the most pathogenic and elaborate other extracellular enzymes, such as staphylokinase, lipase, hyaluronidase, DNase, coagulase, and lysozyme. Coagulase-negative Staphylococci, including S. epidermidis also produce potentially destructive toxin. ${ }^{60}$ Streptococcal toxins include Streptolysin O and S, erythrogenic toxin and the enzymes hyaluronidase, streptodornase, and streptokinase. The invasiveness of S. pneumoniae is aided by collagenase activity, ${ }^{61}$ although the organism may be inherently invasive without toxin production.

The lipopolysaccharides composing the endotoxins within the cell wall of Gram-negative bacteria may be released upon the death of the organism. These lipopolysaccharides may result in the production of stromal rings. These rings have been shown to consist of polymorphonuclear leucocytes within the corneal stroma, which have been chemoattracted by the alternative complement pathway. ${ }^{62,63}$ In addition to occurring with Gram-negative bacterial keratitis, such ring infiltrates have been described in fungal, viral, and acanthamoebal keratitis. In nonbacterial corneal infection, these stromal rings are thought to result from antigen-antibody precipitants (immune rings).

\section{Treatment}

In general, because of the potential rapid destruction of corneal tissue that may accompany bacterial keratitis, if there is a clinical suspicion suggestive of a bacterial pathogen, the patient should be treated appropriately for bacterial keratitis until a definitive diagnosis is established. The objective of therapy in bacterial keratitis is to eliminate the infective organism in a rapid fashion, reduce the inflammatory response, prevent structural damage to the cornea, and promote healing of the epithelial surface. ${ }^{3}$

With suspected infectious keratitis, the clinician has the option based on the clinical impression and severity of the keratitis of initiating specific directed or broadspectrum antimicrobial therapy, or deferring treatment pending the results of laboratory investigation, or monitoring clinical signs. ${ }^{64,65}$ The initial therapy selection is based on the clinical features, antecedent risk factors, and familiarity with the most likely responsible corneal pathogen(s) and their respective antimicrobial susceptibility patterns. ${ }^{66}$

A basic plan for therapy of severe suppurative keratitis depends on the results of Gram stains on smears from diagnostic corneal scrapings. ${ }^{2}$ Inherent in such a therapeutic plan is confidence in the quality of specimen obtained and the technical proficiency of the microbiology laboratory in the processing and interpretation of the clinical material. Evaluation of diagnostic smears with Gram stain is a relatively insensitive method for diagnosis of bacterial keratitis. With optimal conditions, pathogen(s) can be identified with microscopic analysis of Gram-stained smears in about $75 \%$ of monobacterial keratitis and $37 \%$ of polybacterial keratitis cases. ${ }^{3}$ Screening of smears from corneal scrapings with acridine orange and fluorescent microscopy is more sensitive than Gram stain, ${ }^{67,68}$ raising the sensitivity to approximately $80 \%$. Given the $20-30 \%$ possibility of a false-negative interpretation of smears from corneal scrapings, the ophthalmologist must base initial therapy on the clinical assessment of severity. If the Gram stain is equivocal or there is uncertainty in interpretation of diagnostic smears, broad-spectrum antibiotic coverage should be initiated in the initial treatment of all cases of severe suppurative microbial keratitis since the consequences of inappropriate or inadequate therapy can be devastating. ${ }^{65}$

The design for drug administration in severe suppurative keratitis includes antibiotics administered frequently. Owing to the rapid evolution to perforation in keratitis because of virulent pathogens and visual loss secondary to central corneal scarring, many patients with bacterial keratitis having significant ulceration may require hospitalization in the absence of adequate support and assistance. The high frequency and intense dosage scheduling of antimicrobial therapy often requires assistance of trained nursing personnel. Frequent antibiotic administration required for therapy of severe bacterial keratitis can often fatigue even highly motivated patients and family members, resulting in decreased compliance. In the absence of severe fulminant keratitis with impending perforation, patients having mild to moderate keratitis may be managed as outpatients with close monitoring. ${ }^{69}$ Indeed, the availability of highly potent topical antibacterial solutions has permitted outpatient management of bacterial keratitis in all but the most severe cases.

With the goal of rapid cessation of replication and elimination of the bacterial pathogen, selection of appropriate therapy requires an effective drug having minimal toxicity. The results of laboratory investigations assist the clinician in selecting the most specific and efficacious treatment based on results from microbial culture and antimicrobial susceptibility data.

\section{Initial topical antibiotic therapy}

The large number of active antimicrobial drugs available to the treating clinician offers the patient with bacterial keratitis a greater chance for cure with less drug-related toxicity while providing alternative choices despite the continuing emergence of drug-resistant pathogenic 
organisms. In addition to considering the possible organism(s) involved, most effective classes of antibacterial agents, and the possibility of organism resistance, variation in patient response, that is predicting the response of an individual patient to both the organism and the proposed therapy, aids the ophthalmologist in determining the most effective, least toxic agent(s) for treatment. Additional criteria required to identify the actual drug(s) of choice for a particular patient include outpatient $v s$ in-patient management and cost.

Although some organisms continue to be predictably susceptible to selected antimicrobial agents, the development of clinically important resistant isolates is common because of the high selective pressures applied by intense antibiotic usage. Mechanisms of organism resistance include plasmid transfer, either by conjugation or transduction and chromosomal mutations. The rate of the emergence of mutation and the extent of resistance may vary between organisms and from drug to drug. Depending upon the mechanism and degree of resistance, the administration of larger dosages of drug that do not cause serious adverse effects may be adequate for clinical cure. With corneal infection, an advantage is direct accessibility via topical route of administration to achieve high tissue concentrations without significant systemic or local side effects. In contrast, effective treatment of certain infections, such as nontuberculous Mycobacterial keratitis, often requires combinations of antimicrobial drugs to avoid the rapid development of highly resistant strains that appear when single agent therapy is used. Antimicrobial susceptibility testing is recommended whenever there is doubt about the potential susceptibility of a given pathogen. Patterns of antimicrobial susceptibility may vary from one geographic area to another, among different hospitals in a given area, between clinics within a single building, and between community-acquired and hospital-acquired infections. With community-acquired bacterial keratitis, antibiotic resistance is infrequently encountered and usually surmounted with intensive topical dosing. Nosocomial corneal infections as with those sustained in patients maintained on chronic mechanically assisted ventilation with exposure keratopathy in intensive care or burn units should be monitored closely for high-level organism resistance.

Apart from the virulence of the organism, severity of corneal infection is also determined in part by the age, genetic makeup, and general health of the patient. Deficiencies of humoral and cellular defense mechanisms negatively impact patient response to therapy. Factors that may limit the use of a particular agent in an individual include a reliable history of an allergic reaction to the antibiotic (rash, urticaria, angioedema, wheezing, or anaphylaxis), potential adverse interactions, and predictable adverse effects in certain clinical situations (eg use of tetracyclines in young children or pregnant women).

Outpatient $v s$ in-patient drug therapy modes are distinguished primarily by the severity of the keratitis and the anticipated compliance with treatment. Among possible efficacious alternatives, low toxicity and ease of administration are the most important factors in selection of drug therapy for outpatients. Potency of the antiinfective agent with requirement for less frequent administration may improve compliance. With severe keratitis and the potential for permanent structural alteration, the rapid attainment of inhibitory, preferably bactericidal concentration within corneal tissues is the primary consideration often over-riding factors such as convenience and localized toxicity.

The impact of a drug cost is an increasingly important variable in therapeutic choices. Owing to the potential devastating effects of severe keratitis, the ophthalmologist's primary responsibility is selection of the antimicrobial agent(s) that is most likely to effect a complete cure in the shortest time. In some instances, selection of an appropriate, equally effective, but less expensive, preparation may ensure compliance in patients having mild to moderate keratitis. The ophthalmologist should make therapeutic comparisons based on unbiased sources of information assessing the cost of equally effective preparations.

\section{Routes of administration}

One of the fundamental principles of pharmacotherapy is to maximize the amount of drug that reaches the site of action in sufficient concentration to cause a beneficial therapeutic effect. ${ }^{70}$ Topical application is the main stay of ocular drug delivery systems and the topical route is the preferred method of application of antibiotics in therapy for bacterial keratitis. ${ }^{71-73}$ Eyedrops are the most common route of antibiotic delivery to the eye. Other topical preparations, including ointments, gels, and sustained release vehicles, are used to achieve higher concentrations of antibiotics in the corneal stroma. Drug penetration into the cornea may be increased with higher concentrations, greater lipophilicity, more frequent applications, and enhanced contact time using certain vehicles. ${ }^{74,75}$ The corneal epithelium represents a potential barrier to antibiotic penetration and absence of the epithelium, as with ulcerative keratitis, often enhances drug penetration. Fortified concentrations of antibiotics are more effective and preferred to the commercial strength of many antibiotics. ${ }^{71}$ Fluoroquinolone antibiotics may be effective at their commercial concentrations in therapy for bacterial 
keratitis given their relative high potency. ${ }^{20}$ Fortified topical antibiotics applied every $30 \mathrm{~min}$ are equally effective to administration every $15 \mathrm{~min} .{ }^{76}$ To achieve rapidly peak corneal concentrations, a 'loading' dose of antibiotic is initiated with frequent, repetitive administration. ${ }^{77}$ Antibiotic solutions are preferred to ointment formulations because of the ease of altering the concentration of the solution as opposed to the ointment form. Ointments have the theoretical advantages of prolonged contact time, lubricating properties for the ocular surface, high viscosity to resist dilution with reflex tearing, and ease of administration. Peak corneal drug concentrations may be limited compared to achievable levels with antibiotic solutions since the ointment must dissolve in the preocular tear film before it can penetrate into the cornea. ${ }^{78}$ Antibiotic ointment preparations do not appear to adversely deter wound healing. ${ }^{79}$ Fortified antibiotics are prepared by diluting the desired amount of parenteral compound with an appropriate vehicle, such as artificial tear solution or balance salt solution. Caution should be exercised to avoid mixing two antibiotics together. Different antibiotic chemical structures may result in varying stabilities in aqueous solution. Fortified cephalosporins and aminoglycosides remain stable and maintain potency in aqueous solution for at least 1 week without significant loss of antibiotic activity. ${ }^{80}$

The initial loading dose of antibiotic is achieved with topical administration of one drop every $2 \mathrm{~min}$ for five applications. Antibiotics are then administered every $30 \mathrm{~min}$ (alternating drugs when multiple antibiotics are employed) for the first 24-36 h, depending on initial clinical severity judgement. If there is difficulty obtaining fortified antibiotic formulations, therapy should be initiated with very frequent commercial strength antibiotic application without delay. An advantage of the available fluoroquinolone ophthalmic solutions is their high potency, stability at room temperature, and broad spectrum of antibacterial activity at commercial strengths. Subconjunctival injection of antibiotics can result in high corneal drug concentrations via diffusion and by leakage through the injection site. ${ }^{81}$ Topical fortified tobramycin therapy resulted in a greater reduction of Pseudomonas organisms than did subconjunctival injection of tobramycin in experimental keratitis. ${ }^{31}$ Topical administrations of fortified antibiotics appear just as effective as subconjunctival antibiotic injection for therapeutic effect. ${ }^{82,83}$ Subconjunctival administration of antibiotics may provoke patient anxiety, pain, subconjunctival haemorrhage, and conjunctival scarring. Depending on the agent administered, $\mathrm{pH}$, and osmolarity, injection may result in significant toxicity to the conjunctiva. Toxicity may lead to conjunctival scarring, which may make any subsequent conjunctival surgery more difficult. With conjunctival chemosis and inflammation, the potential for inadvertent penetration and intraocular administration is an additional concern. Based on the clinical evidence, there appears to be no therapeutic advantage of subconjunctival antibiotic administration vs topical fortified application. ${ }^{84-86}$

Subconjunctival antibiotic injections may be indicated in certain clinical situations, such as impending corneal perforation, where fortified topical antibiotics cannot be reliably delivered because of patient compliance. The pain from subconjunctival injections may be reduced by adjusting the $\mathrm{pH}$ of the antibiotic solution if possible. The conjunctiva may be anaesthetized prior to administration with topical proparacaine and injection of

subconjunctival xylocaine $1 \%$ solution $(0.25 \mathrm{ml}$ delivered through a 30-gauge needle) prior to antibiotic administration in the same area. Subconjunctival injections may be repeated every $12-24 \mathrm{~h}$ at separate sites during the initial $24-48 \mathrm{~h}$. Continuous lavage of antibiotic may deliver a high concentration and mechanical irrigation to remove potential virulence factors. ${ }^{87,88}$ Continuous lavage or infusion via a scleral contact lens (Mediflow) is costly and impractical because of the requirement of patient immobilization. In addition, such therapy may result in epithelial trauma, cumulative toxicity of the ocular surface, or systemic toxicity. Hydrophilic soft contact lenses may act as a tear film antibiotic retention device and enhance penetration by prolonging the relative contact time. ${ }^{89,90}$ If corneal ulceration is marked, the temporary use of a therapeutic soft contact lens may facilitate stromal repair and promote re-epithelialization by protecting the corneal surface from mechanical trauma of lid movement. Collagen corneal shields soaked in antibiotic solutions have also been shown to increase antibiotic penetration compared with therapeutic soft contact lenses. ${ }^{91,92}$ Collagen corneal shields have been effective adjuncts in the therapy of experimental bacterial keratitis. ${ }^{93}$

Polymer inserts have also been designed to prolong the presence of drug in the preocular tear film. ${ }^{94}$ Temporary intracanalicular collagen implants may also prolong the retention of antibiotics in tears and increase stromal concentration to enhance bacterial killing in experimental keratitis. ${ }^{95}$ Liposomal systems have been designed to improve the interaction of drugs with the corneal surface to enhance potentially the safe delivery of antibiotics. ${ }^{96}$ Transcorneal iontophoresis of antibiotics has also been employed to increase attainable drug concentrations and increase efficacy of antibacterial therapy. ${ }^{97,98}$

Antibiotics administered via the parenteral route are relatively poorly absorbed into the noninflamed eye. Bactericidal corneal tissue levels can only be achieved at the risk of systemic toxicity. Bacterial keratitis with 
accompanying ocular inflammation may enhance the ocular penetration of systemic antibiotics. ${ }^{99}$ Severe gonococcal keratoconjunctivitis should be treated with systemic antibiotics, in addition to topical antibiotics to prevent possible ulcerative keratolysis and perforation. Severe keratitis due to $H$. influenzae or P. aeruginosa in young children should be treated with parenteral, as well as local antibiotics to reduce the risk of systemic spread. ${ }^{100}$ Parenteral antibiotics are indicated in severe keratitis with impending perforation, perforated infections with potential for intraocular spread, following perforating injuries to the corneosclera, or with contiguous scleral involvement.

\section{Antibiotic therapy}

The objective for initial antibiotic selection in therapy for bacterial keratitis is rapid elimination of the corneal pathogen(s). No single topical antibiotic is effective against all potential organisms causing bacterial keratitis. Thus, selection of an antimicrobial agent having a broad spectrum of activity, including the most likely Grampositive and Gram-negative corneal pathogens, is desirable. Historically, a combination of two compounds with one directed against the Gram-positive pathogens and the other against the Gram-negative organisms was considered a rational initial treatment choice. ${ }^{3}$ Although penicillin-G is superior in activity against $S$. pneumoniae and other Streptococci, the frequency of penicillinaseproducing Staphylococci and other organisms requires a penicillinase-resistant agent. Cephalosporins evolved as the drug of choice against unidentified Gram-positive cocci. Cefazolin $(50 \mathrm{mg} / \mathrm{ml})$ is well tolerated by the ocular surface with topical and subconjunctival routes of administration. Additionally, it can be employed in therapy of selected patients having a prior history of allergy to penicillin.

Aminoglycosides were the preferred initial antibiotic choice for therapy of suspected Gram-negative keratitis. Gentamicin evolved as the initial aminoglycoside agent of choice owing to its favourable pharmacokinetics and excellent activity against Pseudomonas, Klebsiella, Enterobacter, and other Gram-negative species. With the emergence of gentamicin-resistant strains of $P$. aeruginosa, tobramycin has become an alternate initial choice.

Approximately $10 \%$ of corneal isolates of Pseudomonas may be resistant to aminoglycosides, with some strains being resistant to gentamicin, but sensitive to tobramycin. ${ }^{101}$

In addition to coverage of Gram-positive cocci, the cephalosporin may provide some activity against Gramnegative rods. The third-generation cephalosporins provide greater Gram-negative coverage, yet have less Gram-positive activity than first-generation cephalosporins. Combined therapy with topical fortified cefazolin (or other cephalosporin) and tobramycin (or gentamicin) became the rational initial therapeutic recommendation for polybacterial keratitis or when results of Gram stain were equivocal. ${ }^{3}$ Aminoglycosides, especially tobramycin, have considerable toxicity when administered topically at frequent intervals for a prolonged period.

The fluoroquinolone antibiotics have potent bactericidal activity against the broad spectrum of Gramnegative aerobic bacteria and many Gram-positive bacteria, including penicillinase-producing and methicillin-resistant Staphylococci. The fluoroquinolones have now been shown in two separate independent trials to provide a safe and effective therapy for acute bacterial keratitis when compared with combination fortified antibiotic treatment. ${ }^{102,103}$

Penicillin-G at a concentration of $100000 \mathrm{U} / \mathrm{ml}$ remains the initial drug of choice for keratitis caused by Streptococcal species, including S. pneumoniae. Some penicillin-resistant pneumococcal strains have recently been identified. Penicillinase-producing strains of $N$. gonorrhoeae have been introduced and observed in ocular infections. Owing to a relatively high prevalance of $N$. gonorrhoeae resistant to penicillin, alternate drug choices, such as ceftriaxone, should be selected. If Grampositive branching filaments are observed on microscopic examination of smears from corneal scrapings, penicillin may be an appropriate choice for the possible Actinomycetales organism pending final identification.

\section{Modification of therapy}

The results of microbial culture and antimicrobial susceptibility testing data may suggest a modification from the initial therapeutic plan. If the identified organism is likely to be significantly more susceptible to an antibiotic other than the one originally selected, or if antibacterial susceptibility testing confirms resistance, the more effective drug may be substituted. If combination broad-spectrum therapy was initially selected and a single organism is isolated, the less effective agent may be discontinued. If microbial culture fails to grow a causative organism, clinical judgement must be exercised to guide further antimicrobial therapy.

Any modification of therapy should be based on the clinical response and patient tolerance to initial therapy, as well as the laboratory data. The initial judgement of clinical severity also impacts decisions to modify therapy. If there is substantial clinical improvement on the initial antibiotic course, there may be no advantage to selection of an alternative agent.

For anaerobic organisms, including Gram-positive cocci or Gram-negative rods, penicillin remains the 
preferred agent. Aerobic and anaerobic Gram-positive rods may also respond to penicillin therapy.

A combination of trimethoprim $(16 \mathrm{mg} / \mathrm{ml})$ and sulphamethoxazole $(80 \mathrm{mg} / \mathrm{ml})$ eyedrops is an effective treatment for Nocardia keratitis. ${ }^{104}$ Sulphonamides, tetracyclines, erythromycin, or amikacin may be alternate agents.

The recommended initial therapy of acid-fast-stained positive corneal scrapings in suspected microbial keratitis is topical amikacin $10-20 \mathrm{mg} / \mathrm{ml}$, one drop every half hour as indicated. ${ }^{105}$ Subconjunctival amikacin $20 \mathrm{mg}$ in $0.5 \mathrm{ml}$ may be adjunctively administered. Systemic amikacin is not routinely utilized, but may be added in selected cases with corneal perforation or extension of infection to involve the sclera. Other antibiotics reported to be effective against a significant number of isolates of $M$. fortiutum and M. chelonae include cefoxitine, ciprofloxacin, doxycycline, erythromycin, imipenem, kanamycin, netilmicin, ofloxacin, and tobramycin. Sulphamethoxazole may sometimes have significant activity.

The fluoroquinolones have been shown to be active against the most important nontuberculous mycobacteria causing keratitis, including some species that are highly resistant to standard antituberculous drugs. M. fortuitum is highly susceptible to both ciprofloxacin and ofloxacin. ${ }^{106,107}$ The minimal inhibitory concentrations of ciprofloxacin have varied from 0.01 to $12.5 \mu \mathrm{g} / \mathrm{ml}$. The MICs of ofloxacin have ranged from 0.03 to $1.2 \mu \mathrm{g} / \mathrm{ml}$ and no resistant strains have been identified. Experimental animal models and isolated clinical reports ${ }^{108}$ have suggested that topical ciprofloxacin alone or in combination with topical amikacin may be useful in the treatment of M. fortuitum keratitis. Experimental studies assessing the in vivo efficacy of newer macrolides, including clarithromycin and azithromycin, ${ }^{109,110}$ suggest a potential role in the therapy of $M$. fortuitum keratitis.

The therapy of nontuberculous mycobacterial keratitis is complicated by the relatively poor correlation between in vitro susceptibility profiles and clinical behaviour. Following initial response, the infection may worsen, even if the pathogen remains 'sensitive' by in vitro susceptibility testing.

The response of bacterial keratitis to antibiotic therapy must be monitored with frequent clinical observation. Slit-lamp biomicroscopic examination twice daily on hospitalized patients should be performed. The response to therapy may be difficult to appreciate with assessment within the first few days owing to organism and host factors increasing inflammation, and the reaction to corneal scrapings, as well as frequent local antibiotics. Within $48-72 \mathrm{~h}$ of effective bactericidal therapy, the progression of keratitis is halted. The stromal infiltrate consolidates, the anterior chamber inflammation subsides, and the epithelial and stromal healing begins. Clinical response varies depending on the responsible pathogen, duration of infection, antecedent factors, and host response. After 36-48 $\mathrm{h}$, the frequency of antibiotic administration can be tapered. Caution with cessation of therapy is recommended for organisms that may persist in corneal tissue, such as P. aeruginosa, and prolonged therapy may be required. The principal end points of treatment are re-epithelialization and nonprogression of stromal infiltrates. The patient should be monitored for tolerance of antimicrobial agents, as toxicity may retard epithelial and stromal healing. In addition, resistant organisms may fail to respond appropriately to topical therapy.

\section{Adjunctive therapy}

Owing to the rich innervation of the cornea, ulcerative keratitis is frequently accompanied by significant pain. Pain control with acetinominophen or other analgesics may result in improved patient comfort and more effective delivery of the treatment regimen. Topical cycloplegic agents should be administered to relieve ciliary spasm, alleviate pain, and to prevent the formation of synechiae. Topical $0.25 \%$ scopolamine or homatropine $5 \%$ used t.i.d. to q.i.d. is usually adequate. Significant intraocular inflammation may result in a secondary glaucoma. Elevated intraocular pressure should be monitored and treated with topical beta blocker or topical or oral carbonic anhydrase inhibitors as required for control. Most patients can be effectively managed as outpatients, if there is an adequate support system to allow compliance with the treatment plan.

Patching should be avoided in the initial therapy of bacterial keratitis, as this may result in a microenvironment favourable to accelerated organism replication. Following eradication of the causative bacteria, patching may be applied to assist reepithelialization. Therapeutic soft contact lenses may be a useful adjunct to assist epithelial healing. Antibiotic administration should continue over the therapeutic soft contact lens. Caution should be exercised as infection may occasionally complicate therapeutic soft contact lens usage. ${ }^{111}$ The therapeutic lens may provide some tectonic support with impending or microscopic corneal perforation.

One of the principal objectives of therapy for bacterial keratitis is to prevent tissue destruction and irreversible structural alterations. A number of adjunctive modalities have been suggested to reduce the destructive effects of various enzymes released with progressive bacterial keratitis. Injured corneal epithelium, infiltrating neutrophils, and some bacterial organisms elaborate various enzymes that contribute to stromal keratolysis. 
Collagenase is also produced by host corneal tissue. Enzyme inhibitors, including disodium edetate (EDTA $0.05 \mathrm{M}$ ), or acetylcysteine (Mucomyst, 20\%) or Heparin $2 \%$ have been shown to be effective experimentally. ${ }^{112-114}$

Matrix metalloproteinases (MMPs) play an important role in corneal wound healing and in pathologic conditions. The activity of these proteases is regulated by the presence of tissue inhibitors of metalloproteinases. Infectious ulcerative keratitis may be modified by controlling the MMP activity in the tissue. MMP-2 is a normal constituent of the corneal stroma, but MMP-9 is found under pathologic conditions and after corneal wounding. Both MMP-2 and MMP-9 have the capacity to degrade basement membrane collagens (types IV and VII). TGF-beta augments the expression of MMP-9 in corneal tissue. Synthetic inhibitors of matrix metalloproteinase have been shown to inhibit proteases from $P$. aeruginosa in vitro and to prevent experimental Pseudomonas keratitis. ${ }^{115}$ In addition, synthetic metalloproteinase inhibition may potentiate the antiangiogenic effect of high-dose prednisolone for inhibition of endotoxin-induced corneal neovascularization in rabbits. ${ }^{116}$ Clinical trials assessing the potential adjunctive role of synthetic matrix metalloproteinase inhibitors are nearing completion.

The precise role and the timing of adjunctive topical corticosteroid usage in the therapy of bacterial keratitis has remained controversial. Reduction in the host inflammatory response which may contribute to corneal destruction provides the rationale for corticosteroids usage. Corticosteroids effectively decrease the host inflammatory response initiated by bacterial exo- or endotoxins and lytic enzymes released from polymorphonuclear neutrophils. Several experimental studies have failed to demonstrate any deleterious effect from the addition of topical corticosteroids with concomitant bactericidal therapy for bacterial keratitis. ${ }^{117-119}$ Microbial cultures from patients with keratitis after 3 days of gentamicin therapy grew more bacteria in individuals receiving topical corticosteroids, with a longer treatment course required to eradicate the infection using this combined treatment. ${ }^{120}$ Combined antibiotic therapy with adjunctive corticosteroids did not improve the clinical course of experimental Pseudomonas keratitis compared with treatment with antibiotic alone regardless of the timing or strength of corticosteroid therapy. ${ }^{121}$ Enhancement or recurrence of Pseudomonas keratitis has been observed with concomitant corticosteroid and antibiotic treatment. ${ }^{122,123}$

Prior use of corticosteroids may mask the clinical signs of stromal and intraocular inflammation, such that bacterial invasion may not be detected. Antecedent use establishes the potential for severe rebound stromal inflammation with keratolysis after withdrawal of corticosteroids during the initial management of infection. Severe keratitis with marked stromal thinning may accelerate to corneal perforation with corticosteroid usage.

Corticosteroids may have a limited role in the therapy of bacterial keratitis to suppress the deleterious effects of inflammation once effective bactericidal therapy has eliminated or reduced the pathogen(s). With Grampositive keratitis, judicious topical application of corticosteroid may be initiated after several days of intensive specific antimicrobial therapy. In confirmed Gram-negative infection, or if there is doubt regarding a possible Gram-negative coinfection, corticosteroid therapy should be deferred for a longer period of aggressive specific topical antibiotic therapy. Some clinicians recommend withholding steroids if clinical improvement is progressing without steroids, using steroids only after several days of antibiotics if there is persistent inflammation that does not seem to improve, concomitant antibiotic coverage when steroids are used, avoidance of steroids in thin corneas with threatening perforation, and use of steroids for $24 \mathrm{~h}$ prior to a therapeutic penetrating keratoplasty for active bacterial keratitis. ${ }^{124}$ Topical corticosteroids may be administered in low concentrations and infrequent dosing for 1-2 days on a trial basis to monitor for adverse effects and increased as indicated. Long-acting periocular corticosteroids and oral corticosteroids should be avoided in bacterial keratitis.

Cryotherapy has been applied in experimental animal models with demonstration of bactericidal effects. ${ }^{125}$ Cryotherapy may be useful in select cases of focal peripheral corneal ulcerations or in Pseudomonas sclerokeratitis. ${ }^{126,127}$ Caution should be exercised with the administration of cryotherapy, as severe toxic effects may be additive to the keratitis process.

The precise role for adjunctive topical nonsteroidal therapy for bacterial keratitis is not determined. Diclofenac sodium $0.1 \%$ therapy did not adversely effect the results of antibiotic therapy with gentamicin $0.3 \%$ in the treatment of experimental Pseudomonas keratitis. ${ }^{128}$ In an experimental model of Pseudomonas keratitis in rabbits, recurrence was observed in $85 \%$ of steroidtreated rabbits vs $12.5 \%$ of flurbiprofen-treated rabbits. ${ }^{129}$ Conversely, in a S. pneumoniae model, there were no recurrences experienced, either with steroids or nonsteroidal topical treatment. ${ }^{130}$

The application of tissue adhesive (isobutyl cyanoacrylate) or other analogues has been recommended in progressive stromal keratolysis, with thinned Descemetoceles, or small perforated infectious ulcerations. The tissue adhesive may have some inherent antibacterial activity. ${ }^{130}$ It is toxic to corneal endothelium and thus should be applied only for small perforations. 
Tissue glue is useful to restore the integrity of the anterior segment and to postpone the need for surgery until antibiotic and anti-inflammatory therapy have reduced the ocular inflammation. The edges and bed of the ulceration should be debrided and dried with methylcellulose sponges prior to the application of tissue adhesive. A therapeutic soft contact lens should be placed over the tissue adhesive to prevent irritation and to protect the glue from mechanical effects of the eyelids. Tissue toxicity, microbial colonization, use of therapeutic soft contact lenses, and long-term broad-spectrum antibiotics may precipitate tissue adhesive-related microbial keratitis. ${ }^{131}$ Masking of the underlying infection and the development of resistant organisms should be considered when using tissue adhesive.

Excimer laser photoablative treatment of microbial keratitis has been investigated in experimental animal models. ${ }^{132,133}$ Results of these investigations indicate that advanced stromal keratitis with deep suppuration cannot be eradicated using the excimer laser. As corneas may be perforated inadvertently during treatment, excimer laser therapy of infectious keratitis should be approached with caution and used only for very select superficial and well-circumscribed lesions. Carbon dioxide laser therapy has also been investigated in experimental $P$. aeruginosa keratitis. ${ }^{134}$

Corneal patch grafting may be an alternative to the application of tissue adhesives for small corneal perforations resulting from bacterial keratitis. Small partial conjunctival flaps may be used in peripheral ulcerations to assist with healing, but are not recommended for use in impending or perforated central bacterial keratitis. If there is a large perforation or a residual necrotic cornea, a therapeutic penetrating keratoplasty may be indicated. ${ }^{135}$ Maximal antibiotic therapy to eradicate the corneal pathogen(s) and to reduce inflammation are recommended prior to surgery. In addition to topical intensive antibiotic treatment, parenteral antibiotic therapy should be instituted in the perioperative period. The surgeon must select a large trephine to completely excise the area of infection. A freehand dissection may be required in limbal to limbal suppurative keratitis. Sclerocorneal grafting may be performed, although with a limited postoperative success because of glaucoma, rejection, and other problems. An oversized graft $(0.50-0.75 \mathrm{~mm})$ is recommended. A portion of the corneal button should be excised and placed in tissue media for grinding and culture of the tissue homogenate. The remainder of the specimen should be submitted for histopathologic study, including special stains for light microscopy and electron microscopy where indicated. Placement of interrupted sutures is recommended over continuous running sutures, given the intense inflammatory reaction.
Aggressive topical corticosteroids should be applied in the postoperative period along with concomitant antibiotic therapy as indicated. Parenteral therapy should be continued if there is suspicion for intraocular dissemination. Therapeutic penetrating keratoplasty was successful in restoring anatomic and visual results in 75\% of grafts performed for bacterial keratitis in one study. ${ }^{136}$

Complicated cataract may result from severe bacterial keratitis. ${ }^{137}$ Cataract may result from bacterial toxins, iridocyclitis, and treatment toxicity. Cataract formation may result from severe bacterial keratitis alone, but is probably enhanced by concurrent treatment with highdose topical corticosteroids. Surgical rehabilitation may require combined cataract extraction with penetrating keratoplasty, depending on the degree of corneal scarring and opacification with cataract formation.

\section{The new frontier: microbial genomics and proteomics}

While frequent administration of topically applied antimicrobial agents has served patients and ophthalmic clinicians well in therapy of severe infectious keratitis, newer tools are required to enhance our understanding of the molecular pathogenesis of infections involving the cornea. Advances in microbial genomics and proteomics offer the exciting potential to develop new therapeutic targets involved in the cascade of events that is triggered by onset of bacterial keratitis. Such advances shall hopefully elevate treating clinicians beyond the 'exorcist approach' to a more sophisticated strategy of addressing not only the invading organism(s) but the host response as well.

The availability of complete genome sequences has dramatically changed the opportunities for developing novel and improved therapies as well as preventive strategies, including vaccines. ${ }^{138}$ Complete genomic databases provide an inclusive catalogue of all potential candidate vaccines for any bacterial pathogen. In conjunction with adjunct technologies, including bioinformatics, random mutagenesis, microarrays, and proteomics, a systematic and comprehensive approach to identifying vaccine discovery can be undertaken. Genomics must be used in conjunction with population biology to ensure that the vaccine can target all pathogenic strains of a species. A proof in principle of the utility of genomics is provided by the recent exploitation of the complete genome sequence of $N$. meningitidis group B. ${ }^{138}$

Compounding the threat from newer pathogens is the rapid evolution of drug resistance by microorganisms that is rendering many existing antimicrobial agents obsolete. Thus, there is an urgent need for the development of new classes of antimicrobial agents and the identification of new drug targets. In the last two 
decades, the search for completely novel antibacterial agents has acquired a new sense of urgency because of the remarkable rise of antibiotic resistance among key bacterial pathogens. More recently, the advent of bacterial genomics has provided investigators with the data and bioinformatic tools to identify rationally novel antibacterial targets and the genome-scaled methodologies to validate them. ${ }^{139}$ Less than a decade has elapsed since the publication of the first complete bacterial genome sequence, but more than 50 complete microbial genome sequences are now available. Advances in high-throughput automated DNA sequencing have delivered a wealth of genetic information in the form of whole-genome sequences of microbial pathogens. Coupled with this advancement has been the development of new genetic tools and computational advances capable of selecting genes of particular interest as well as testing for the effects of candidate drugs. The existing bacterial genome data set provides both advantages and limitations for the rational identification of novel antibacterial targets. ${ }^{139}$ Since the ability to identify rapidly essential genes where loss of function is coincident with loss of viability is the most important task of genomics-based target validation, essential testing methodologies (in which molecular genetic techniques are used to determine whether or not a gene product is required for viability of the parent cell) are critical and their amenability to genome-scaled analysis exceptionally important.

For example, the emergence and dissemination of drug-resistant pneumococcal strains, coupled to changing patterns of virulence and the inadequacy of available vaccines, calls for an aggressive search for novel targets for antibiotic and vaccine development. ${ }^{140}$ Microbial genomics techniques allow genetic and biochemical tools to be employed to tackle discovery, design, and development of new anti-infective agents based on the identification of hundreds of new targets. Novel approaches have been employed to identify potential antibiotic and vaccine targets in S. pneumoniae. Recently identified virulence factors, as well as molecules essential for bacterial viability, cell wall integrity, and infectivity, have been explored as new potential targets in the battle against pneumococci. ${ }^{140}$

Structural genomics stands out among the emerging fields of proteomics since it influences the drug discovery process at so many points. Recent developments in protein expression technologies, X-ray crystallography, and NMR spectroscopy provide the essential elements for high-throughput structure determination platforms. ${ }^{141,142}$ Bioinformatics methods to interrogate the resulting data will provide comprehensive, genomewide databases of protein structure. Genomic sequencing and methods for high-throughput expression and protein purification are furthest advanced for microbial genes and so these have been the early targets for structural genomics initiatives. ${ }^{142}$ The information will be invaluable in understanding gene function, designing broad-spectrum small molecule inhibitors and in better understanding drug-host interactions.

The process of prokaryotic drug discovery has been highly successful for over more than half a century, yet the number of exploited bacterial targets is a mere fraction, less than $0.1 \%$ of the potential targets (based on total number of bacterial genes identified by gene sequence projects). ${ }^{143}$ To better understand the potential for drug intervention, multiple paradigms have been established in the pharmaceutical industry, all with some semblance of commonality and uniqueness to provide proprietary positioning, yet no company has been successful to date in taking a genomics approach to the finish line of having a genomics-based drug on the market. The whole bacterial genome sequence data in itself is merely a starting point for drug discovery of novel antibacterial targets and, eventually, drugs. In order to leverage this large amount of data, it is necessary to match an understanding of the microbial physiology of pathogenic bacteria to disease processes and identify the gene products for which intervention may reduce or eliminate the infectious state. Many new molecularbased technologies (proteomics, transcriptional profiling, studies of gene expression in vivo) have originated or have expanded into wider use, and have been made possible by the availability of complete bacterial genome sequence information and subsequent bioinformatic analytic tools.

Proteomics has begun to provide insight into the biology of microorganisms. The combination of proteomics with genetics, molecular biology, protein biochemistry, and biophysics is particularly powerful, resulting in novel methods to analyse complex protein mixtures. Emerging proteomic technologies promise to increase the throughput of protein identifications from complex mixtures and allow for the quantification of protein expression levels.

The techniques of proteomics (high-resolution two-dimensional electrophoresis and protein characterization) are widely used for microbiological research to analyse global protein synthesis as an indicator of gene expression. ${ }^{144}$ The rapid progress in microbial proteomics has been achieved through the wide availability of whole-genome sequences for a number of bacterial groups. Beyond providing a basic understanding of microbial gene expression, proteomics has also played a role in medical areas of microbiology. Progress has been made in the use of the techniques for investigating the epidemiology and taxonomy of human microbial pathogens, the identification of novel 
pathogenic mechanisms, and the analysis of drug resistance. In each of these areas, proteomics has provided new insights that complement genomic-based investigations. A major challenge ahead in proteomics is the analysis of genetically heterogeneous bacterial populations and the integration of the proteomic and genomic data for these bacteria. The characterization of the proteomes of bacterial pathogens growing in their natural hosts remains a future challenge.

As genomics is highly promising for vaccine development, the postgenomic era holds the even greater possibility of rational design of novel vaccines for important human pathogens. ${ }^{145,146}$ The discovery and development of these new vaccines is likely to be accomplished through integrated proteomic strategies. Although most proteomic studies are based on twodimensional gel electrophoresis (2D-PAGE) as a separation technique, new methods have been developed within the past 2 years that provide complementary information concerning microbial protein expression. The 2D-PAGE technique in combination with Western blotting has been successfully applied in the discovery of antigens from Helicobacter pylori, Chlamydia trachomatis, and Borrelia garinii. ${ }^{146}$ Two-dimensional semipreparative electrophoresis has provided complementary information regarding membrane protein expression in a strain of H. pylori. Through two-dimensional liquid chromatography-tandem mass spectrometry, the most comprehensive information to date regarding protein expression in yeast was obtained. This technique may become an important tool in vaccinology.

In the field of infectious diseases, there is an urgent need for global approaches that can efficiently, precisely, and integratively study structural and functional genomics and proteomics of microbial infections (infectomics). ${ }^{147}$ The combination of new (eg DNA and protein microarrays) and traditional approaches (eg cloning, PCR, gene knockout and knockin, and antisense) will help overcome the challenges we are facing today. It is possible that the global phenotypic changes

(infectomes) in microbes and their host during infections are encoded by the genomes of microbial pathogens and their hosts. ${ }^{147}$ These phenotypical changes are expressed in certain environmental conditions, such as the corneal and ocular surface milieu, devoted to specific microbehost interactions. Global drug responses (pharmacomes) in microbes and their host can be detected by genomic and proteomic approaches. Genome-wide approaches to genotyping and phenotyping or expression profiling will eventually lead to global dissection of microbial pathogenesis, efficient and rapid diagnosis of infectious diseases, and the development of novel strategies to control infections. The key fundamental issue of infectious diseases is how to understand the interactions between microbial pathogens and their hosts by using infectomics globally and integratively.

The elucidation of the function of new genes is not a simple matter and human genetic studies have been among the most useful in identifying genes implicated in disease, although homologues, or orthologues, of human genes in mouse, worm, fly, and yeast genomes have also been useful in deciphering gene function. ${ }^{148}$ The advent of genomics has led into the study of protein structure and function under the rubric of proteomics. Proteins function in a cell mostly by interacting with other proteins, and protein interaction maps of cellular circuits are now available. Screening strategies to address protein-protein interactions are being developed, and many drug targets in the future will be directed towards these interactions. In addition to using genetic and analytical approaches for finding new drug targets, chemical libraries can be used to inhibit the activity of new proteins, and thus reveal function. The combination of high-throughput screening with testing compounds for ADME (absorption, distribution, metabolism, and excretion) and toxicity will help in the early clarification of clinical utility of both new drug targets and drug candidates.

Bioinformatics has, out of necessity, become a key aspect of drug discovery in the genomic revolution, contributing to both target discovery and target validation. ${ }^{149}$ Bioinformatics will play an increasingly important role in response to the waves of genome-wide data sources that have become available to the industry, including expressed sequence tags, microbial genome sequences, model organism sequences, polymorphisms, gene expression data, and proteomics. However, these knowledge sources must be intelligently integrated.

The future for application of advances in microbial genomics and proteomics towards more sophisticated management strategies for bacterial infections of the cornea beyond the 'exorcist approach' appears very bright indeed.

\section{References}

1 O'Brien TP, Green WR. Keratitis. In: Mandell GL et al (eds). Principles and Practice of Infectious Diseases, Chap 93, 4th ed. Churchill Livingstone: New York, 1995, pp 1110-1118.

2 Jones DB. A plan for antimicrobial therapy in bacterial keratitis. Trans Am Acad Ophthalmol Otolaryngol 1975; 79: 95.

3 Jones DB. Initial therapy of suspected microbial corneal ulcers II. Specific antibiotic therapy based on corneal smears. Surv Ophthalmol 1979; 24 : 97.

4 O'Brien TP, Hazlett LD. Pathogenesis of ocular infection. In: Pepose JS, Holland GN, Wilhelmus KR (eds). Ocular Infection and Immunity, Chap 15. Mosby: St Louis, MO, 1995.

5 Jones DB. Pathogenesis of bacterial and fungal keratitis. Trans Ophthalmol Soc UK 1978; 98: 367. 
6 Baker NR. Pseudomonas aeruginosa exoenzyme $\mathrm{S}$ is an adhesin. Infect Immun 1991; 59(9): 2859.

7 Hoepelman AIM, Tuomanen EL. Consequences of microbial attachment: directing host cell functions with adhesins. Infect Immun 1992; 60: 1729.

8 Reichert R, Stern GA. Quantitative adherence of bacteria to human corneal epithelial cells. Arch Ophthalmol 1984; 102: 1394.

9 Doig P et al. Role of pili in the adhesion of Pseudomonas aeruginosa to human respiratory epithelial cells. Infect Immun 1988; 56: 1641.

10 Holder IA, Naglich JG. Experimental studies of the pathogenesis of infection due to pseudomonas aeruginosa infection. J Trauma 1986; 26: 118.

11 Nicas TI, Iglewski BH. Toxins and virulence factors of Pseudomonas aeruginosa. In: Sokatch JR (ed). The Bacteria. Vol $X$. The Biology of Pseudomonas. Academic Press: New York, 1986.

12 Iglewski BH, Liu PV, Kabat D. Mechanism of action of Pseudomonas aeruginosa exotoxin A: adenosine diphosphateribosylation of mammalian elongation factor II in vitro and in vivo. Infect Immun 1977; 15: 138.

13 Cryz SJ et al. Role of lipopolysaccharide and virulence of Pseudomonas aeruginosa. Infect Immun 1984; 44: 508.

14 Costerton JW. Pseudomonas aeruginosa in nature and diseases. In: Sabath LD (ed). Pseudomonas aeruginosa: The Organisms, The Disease it Causes and their treatment. Hans Huber: Bern, 1980.

15 Patti JM, Allen PL, McGavin MJ et al. MSCRAMM-mediated adherence of microorganisms to host tissues. Annu Rev Microbiol 1994; 48: 585.

16 Woods DE et al. Role of fibronectin in the prevention of adherence of Pseudomonas aeruginosa to buccal cells. J Infect Dis 1981; 143: 784.

17 Hazlett LD et al. Evidence for $N$-acetylmanosomine as an ocular receptor for $P$. aeruginosa adherence to scarified cornea. Invest Ophthalmol Vis Sci 1987; 28: 1978.

18 Stern GA, Weitzenkorn D, Valenti J. Adherence of Pseudomonas aeruginosa to the mouse cornea: epithelial v. stromal adherence. Arch Ophthalmol 1982; 100: 1956.

19 Hazlett LD, Moon MM, Berk R. In vivo identification of sialic acid as the ocular receptor for Pseudomonas aeruginosa. Infect Immun 1986; 51: 687.

20 Hazlett LD et al. Pseudomonas aeruginosa pili mediate binding to human corneal epithelial glycoproteins. 10th International Congress Eye Research, Stresa, Italy, 1992.

21 Rudner XL et al. Corneal epithelial glycoproteins exhibit Pseudomonas aeruginosa pilus binding activity. Invest Ophthalmol Vis Sci 1992; 33: 2185.

22 Liu X, Hazlett LD, Berk RS. Systemic and topical protection studies using Pseudomonas flagella or pili. Invest Ophthalmol Vis Sci 1990; 31: 449.

23 Rudner XL et al. Pseudomonas aeruginosa pili interact differently with glycosylated proteins of immature cornea. Invest Ophthalmol Vis Sci 1992; 33: 844.

24 Lee KK et al. Mapping the surface regions of Pseudomonas aeruginosa PAK pilin: the importance of the C-terminal region of adherence to human buccal epithelial cells. Mol Biol 1989; 3: 1493-1499.

25 Saiman L, Ishimoto K, Lory S, Prince A. The effect of piliation and exoproduct expression on the adherence of Pseudomonas aeruginosa to receptor monolayers. J Infect Dis 1990; 161: 541.
26 Baum J, Panjwani NJ. Adherence of Pseudomonas to soft contact lenses and cornea: mechanisms and prophylaxis. In: Cavanaugh HD (ed). The Cornea: Transaction of the World Congress on the Cornea, Vol III. Raven Press: New York, 1988.

27 Drake D, Montie TC. Flagella, motility, and invasion virulence of Pseudomonas aeruginosa. J Gen Microbiol 1988; 134: 43-52.

28 Ansorg RA et al. Differentiation of the major flagellar antigens of Pseudomonas aeruginosa by the slide coagulation technique. J Clin Microbiol 1984; 20: 84.

29 Montie TC et al. Motility, virulence, and protection with the flagella vaccine against Pseudomonas aeruginosa infection. Antibiot Chemother 1987; 39: 233.

30 Rudner XL, Hazlett LD, Berk RS. Systemic and topical protection studies using Pseudomonas aeruginosa flagella in an ocular model of infection. Curr Eye Res 1992; 11: 727.

31 Hyndiuk RA. Experimental Pseudomonas keratitis: I. Sequential electron microscopy. II. Comparative therapy trials. Trans Am Ophthalmol Soc 1981; 79: 541.

32 Koch JM et al. Experimental Pseudomonas aeruginosa keratitis from extended wear of soft contact lenses. Arch Ophthalmol 1990; 108: 1453.

33 Cotran RS. New roles for the endothelium and inflammation and immunity. Am J Pathol 1987; 29: 407.

34 Fajardo LF. The complexity of endothelial cells. A review. Am J Clin Pathol 1989; 92: 241.

35 Staugas REM et al. Induction of tumor necrosis factor (TNF) and interleukin-I (IL-I) by Pseudomonas aeruginosa and exotoxin A-induced suppression of lymphoproliferation and TNF, lymphotoxin, gammainterferon, and IL-I production in human leukocytes. Infect Immun 1992; 60: 3162.

36 Berk RS, Beisel K, Hazlett LD. Genetic studies on the murine corneal response to P. Aeruginosa. Proc Soc Exp Biol Med 1983; 172: 488.

37 Hazlett LD, Rosen D, Berk RS. Experimental Pseudomonas eye infection in cyclophosphamide-treated mice. Invest Ophthalmol Vis Sci 1977; 16: 649.

38 Twining S, Lohr KM, Moulder JE. The immune system in the experimental keratitis. A model and early effects. Invest Ophthalmol Vis Sci 1986; 27: 507.

39 Cleveland RP et al. The role of complement in Pseudomonas ocular infections. Invest Ophthalmol Vis Sci 1983; 24: 237.

40 Hazlett LD. Pathogenic mechanisms of P. aeruginosa keratitis: a review of the role of T cells, Langerhans cells, PMN, and cytokines. DNA Cell Biol 2002; 21(5-6): 383-390.

41 Hazlett LD, McClellan SA, Rudner XL, Barrett RP. The role of Langerhans cells in Pseudomonas aeruginosa infection. Invest Ophthalmol Vis Sci 2002; 43(1): 189-197.

42 Kernacki KA, Barrett RP, McClellan S, Hazlett LD. MIP1alpha regulates $\mathrm{CD} 4+\mathrm{T}$ cell chemotaxis and indirectly enhances PMN persistence in Pseudomonas aeruginosa corneal infection. J Leukoc Biol 2001; 70(6): 911-919.

43 Thakur A, Xue ML, Wang W, Lloyd A, Wakefield D, Willcox MD. Expression of macrophage migration inhibitory factor during Pseudomonas keratitis. Clin Exp Ophthalmol 2001; 29(3): 179-182.

44 Hazlett LD, McClellan S, Barrett R, Rudner X. B7/CD28 costimulation is critical in susceptibility to Pseudomonas aeruginosa corneal infection: a comparative study using monoclonal antibody blockade and CD28-deficient mice J Immunol 2001; 166(2): 1292-1299.

45 Hazlett LD, Rudner XL, McClellan SA, Barrett RP, Lighvani S. Role of IL-12 and IFN-gamma in Pseudomonas aeruginosa 
corneal infection. Invest Ophthalmol Vis Sci 2002; 43(2): 419-424.

46 Steuhl KP et al. The effect of immunization on corneal infection by Pseudomonas aeruginosa. Invest Ophthalmol Vis Sci 1987; 28: 1559.

47 Hibbs MS et al. Gelatinase (type IV collagenase) immunolocalization in cells and tissues: use of an antiserum to rabbit bone gelatinase that identifies high and low Mr forms. J Cell Sci 1989; 92: 487.

48 Fini ME, Jirard MT. Expression of collagenolytic/ gelatinolytic metalloproteinase by normal cornea. Invest Ophthalmol Vis Sci 1990; 32: 12779.

49 Kirschner SE, Twining SS. The effect of Pseudomonas aeruginosa exoproducts on corneal proteases. Invest Ophthalmol Vis Sci 1990; 31 (Suppl): 487.

50 Callegan MC, Engel LS, Hill JM, O'Callaghan RJ. Corneal virulence of Staphylococcus aureus: roles of alpha-toxin and protein A in pathogenesis. Infect Immun 1994; 62(6): 2478.

51 Howe TR, Iglewski BH: Isolation and characterization of alkaline protease-deficient mutants of Pseudomonas aeruginosa in vitro and in vivo. Infect Immun 1984; 3: 1058.

52 Ohman DE, Barns RP, Iglewski BH. Corneal infection in mice with toxin-A and elastase mutants of Pseudomonas aeruginosa. J Infect Dis 1980; 142: 547.

53 Burns FR, Gray RP, Patterson CA. Inhibition of alkaliinduced corneal ulceration and perforation by a thio peptide. Invest Ophthalmol Vis Sci 1990; 31: 107.

54 Heck LW, Morihara K, Abrahamson DR. Degradation of soluble laminin and depletion of tissue-associated basement laminin by Pseudomonas aeruginosa elastase and alkaline protease. Infect Immun 1986; 54: 149.

55 Twining SS, Davis SD, Hyndiuk RA. Relationship between proteases and descemetocele formation in experimental Pseudomonas keratitis. Curr Eye Res 1986; 5: 503.

56 Bejarano PA et al. Degradation of basement membranes by Pseudomonas aeruginosa elastase. Infect Immun 1989; 57: 3783.

57 Kharazami A. Mechanisms involved in the evasion of host defense by Pseudomonas aeruginosa. Immunol Lett 1991; 30: 201.

58 Preston $\mathrm{M}$ et al. Kinetics of serum, tear, and corneal antibody responses in resistant and susceptible mice intracorneally infected with Pseudomonas aeruginosa. Infect Immun 1992; 60: 885.

59 Kreger AS et al. Immunization against experimental Pseudomonas aeruginosa and Serratia marcescens keratitis vaccination with lipopolysaccharide endotoxin and proteases. Invest Ophthalmol Vis Sci 1986; 27: 932.

60 Valenton MJ, Okumoto M. Toxin producing strains of Staphylococcus epidermidis. Arch Ophthalmol 1973; 89: 187.

61 Jelyaszewicz J, Wadstrom T (eds). Bacterial Toxins in Cell Membranes. Academic Press: London, 1978.

62 Mondino BJ, Rabin BS, Kessler E et al. Corneal rings with Gram negative bacteria. Arch Ophthalmol 1977; 95: 2222.

63 Belmont JB, Ostler HB, Chandler RD, Schwab I. Noninfectious ring-shaped keratitis associated with Pseudomonas aeruginosa. Am J Ophthalmol 1982; 93: 338.

64 Jones DB. Polymicrobial Keratitis. Trans Am Ophthalmol Soc 1981; 79: 153.

65 Baum JL, Jones DB: Initial therapy of suspected microbial corneal ulcers. Surv Ophthalmol 1979; 24: 97.

66 Wilhelmus KR. Bacterial corneal ulcer. Int Ophthalmol Clin 1984; 24: 1.
67 Gomez JT, Robinson NN, Osato MS et al. Comparison of acridine orange and Gram stains in bacterial keratitis. Am J Ophthalmol 1988; 106: 735 .

68 Groden LR, Rodnite J, Brinser JH, Genvert GI. Acridine orange and Gram stains in infectious keratitis. Cornea 1990; 9: 122.

69 Groden LR, Brinser JH: Out-patient treatment of microbial corneal ulcers. Arch Ophthalmol 1986; 104: 84.

70 O'Brien TP, Reynolds LA. Basic ocular pharmacotherapy. J Ophthalmol Nurs Tech 1995; 14(4): 160.

71 Shell JW: Pharmacokinetics of topically applied ophthalmic drugs. Surv Ophthalmol 1982; 26: 207.

72 Lesar TS, Fiscella RG. Antimicrobial drug delivery to the eye. Drug Intel Clin Pharm 1985; 19: 642.

73 Barza M. Antibacterial agents in the treatment of ocular infections. Infect Dis Clin N Am 1989; 3: 533.

74 Davis SD, Sarff LD, Hyndiuk RA. Topical tobramycin therapy of experimental Pseudomonas keratitis: an evaluation of some factors that potentially enhance efficacy. Arch Ophthalmol 1978; 96: 123.

75 Kupferman A, Leibowitz HM. Topical antibiotic therapy of Pseudomonas aeruginosa keratitis in guinea pigs. Arch Ophthalmol 1979; 97: 1699.

76 Davis SD, Sarff LD, Hyndiuk RA. Antibiotic therapy of experimental Pseudomonas keratitis in guinea pigs. Arch Ophthalmol 1977; 95: 1638.

77 Glasser DB, Gardner S, Ellis JG, Pettit TH. Loading doses and extended dosing intervals in topical gentamicin therapy. Am J Ophthalmol 1985; 99: 329.

78 Robin JS, Ellis PP. Ophthalmic ointments. Surv Ophthalmol 1978; 22: 335.

79 Hanna C, Hof HC, Smith WG. Influence of drug vehicle on ocular contact time of sulfacetamide sodium. Ann Ophthalmol 1985; 17: 560.

80 Osborn E, Baum JL, Ernst C, Koch P. The stability of ten antibiotics in artificial tears. Am J Ophthalmol 1976; 82: 775 .

81 Baum J, Barza M, Hsushan D, Weinstein L. Concentration of gentamicin in experimental corneal ulcers. Arch Ophthalmol 1974; 92: 315.

82 Kupferman A, Leibowitz HM. Antibiotic therapy of bacterial keratitis: topical application or a periocular injection? Invest Ophthalmol Vis Sci 1980; 19: 112.

83 Baum JL, Barza M. Topical versus subconjunctival treatment of bacterial corneal ulcers. Ophthalmology 1983; 90: 162 .

84 Stern GA, Driebe WT: The effect of fortified antibiotic therapy on the visual outcome of severe bacterial corneal ulcers. Cornea 1982; 1: 341.

85 Liebowitz HM, Ryan WJ, Kupferman A: Route of antibiotic administration in bacterial keratitis. Arch Ophthalmol 1981; 99: 1420.

86 Baum J. Treatment of bacterial ulcers of the cornea in the rabbit: a comparison of administration by eyedrops and subconjunctival injections. Trans Am Ophthalmol Soc 1982; 80: 369 .

87 Hessburg PC. Treatment of Pseudomonas keratitis in humans. Am J Ophthalmol 1966; 61: 896.

88 Burris TE, Newsom DI, Rowsey JJ. Hessburg subpalpebral antibiotic lavage of Pseudomonas corneal and corneoscleral ulcers. Cornea 1982; 1: 347.

89 Matoba AY, McCulley JP. The effect of therapeutic soft contact lenses on antibiotic delivery to the cornea. Ophthalmology 1985; 92: 97. 
90 Busin M, Goebbels M, Spitznas M. Medicated bandage lenses for sustained gentamicin release. Ophthalmology 1987; 94 (Suppl): 124.

91 O'Brien TP, Sawusch MR, Dick JD et al. Use of collagen corneal shields versus soft contact lenses to enhance penetration of topical tobramycin. J Cataract Refract Surg 1988; 14: 505.

92 Unterman SR, Rootman DS, Hill JM et al. Collagen shield drug delivery: therapeutic concentrations of tobramycin in the rabbit cornea and aqueous humor. J Cataract Refract Surg 1988; 14: 500.

93 Sawusch MR, O'Brien TP, Dick JD et al. Use of collagen corneal shields in the treatment of bacterial keratitis. Am J Ophthalmol 1988; 106: 279.

94 Baum JL, Barza M, Weinstein L. Preferred routes of antibiotic administration in treatment of bacterial ulcers of the cornea. Int Ophthalmol Clin 1973; 13: 31.

95 Gilbert ML, Wilhelmus KR, Osato MS. Intracanalicular collagen implants enhance topical antibiotic bioavailability. Cornea 1986; 5: 167.

96 Schaeffer HE, Krohn DL. Liposomes and topical drug delivery. Invest Ophthalmol Vis Sci 1982; 22: 220.

97 Rootman DS, Hobden JA, Jantzen JA et al. Iontophoresis of tobramycin for treatment of experimental Pseudomonas keratitis in rabbits. Arch Ophthalmol 1988; 106: 262.

98 Callegan MC, O'Callaghan RJ, Hill JM. Pharmacokinetic considerations in the treatment of bacterial keratitis. Clin Pharmacokinet 1994; 27(2): 129.

99 Cunha-Vaz J. The blood-ocular barriers. Surv Ophthalmol 1979; 23: 279.

100 Burns RP, Rhodes DM. Pseudomonas eye infection as a cause of death in premature infants. Arch Ophthalmol 1961; 65: 517.

101 Gelender H, Rettich C. Gentamicin-resistant Pseudomonas aeruginosa corneal ulcers. Cornea 1984; 3: 21.

102 O'Brien TP, Maguire M, Fink N et al. Results from the bacterial keratitis study: topical ofloxacin versus cefazolin and aminoglycoside in therapy for acute bacterial keratitis. Arch Ophthalmol, 1995.

103 Hyndiuk RA, Eiferman RA, Caldwell DR et al. Comparison of ciprofloxacin $0.3 \%$ (Ciloxan) solution to fortified tobramycin/cefazolin in treatment of bacterial corneal ulcers. Ophthalmology, 1996; 103: 1854-1862.

104 Donnenfeld ED, Cohen EJ, Barza M, Baum J. Treatment of Nocardia keratitis with topical trimethoprim-sulfamethoxazole. Am J Ophthalmol 1985; 99: 601.

105 Swenson JM, Wallace Jr RJ, Silcox VA et al. Antimicrobial sensitivity of five subgroups of Mycobacterium fortuitum and Mycobacterium chelonae. Antimicrob Agents Chemother 1985; $28: 807$.

106 Gay JD, Deyoung DR, Roberts GD. In Vitro activity of norfloxacin and ciprofloxacin against Mycobacterium tuberculosis, M. avium complex, M. chelonei, M. fortuitum, M. kansasii. Antimicrob Agents Chemother 1984; 26: 94.

107 Wallace RJ, Bedsole G, Sumter G et al. Activities of ciprofloxacin and ofloxacin against rapidly growing Mycobacteria with demonstration of acquired resistance following single-drug therapy. Antimicrob Agents Chemother 1990; 34: 65.

108 Hwang DG, Biswell R. Ciprofloxacin therapy of Mycobacterium chelonae keratitis. Am J Ophthalmol 1993; 115: 114.
109 Field JH, Backhoff IK, Dick JD, O'Brien TP. Comparative topical treatment of Mycobacterium fortuitum keratitis in rabbits. Invest Ophthalmol Vis Sci 1993; 34(4): 737.

110 Husain SE, Matoba AY, Husain N, Jones DB. Antimicrobial efficacy of clarithromycin and azithromycin against Mycobacterium chelonae and Mycobacterium abscessus. Invest Ophthalmol Vis Sci 1993; 34(4): 729.

111 Brown SI, Bloomfield S, Pearce DB, Tragakis M. Infections with a therapeutic soft lens. Arch Ophthalmol 1974; 91: 275.

112 Slansky HH, Dohlman CH, Berman MB. Prevention of corneal ulcers. Trans Am Acad Ophthalmol Otolaryngol 1971; 75: 1208

113 Ellison A, Poirier R. Therapeutic effects of heparin on Pseudomonas-induced corneal ulceration. Am J Ophthalmol 1976; 82: 619.

114 Mehra KS, Singh R, Bhatia RPS. Lysozyme in corneal ulcer. Ann Ophthalmol 1975; 7: 1470.

115 Barletta JP, Balch KC, Dimova HG et al. Inhibition of Pseudomonas corneal ulcers by a synthetic matrix metalloproteinase inhibitor (Galardin). Invest Ophthalmol Vis Sci 1993; 34(4): 1749.

116 Brown M, Li WW, Dutt $\mathrm{S}$ et al. A synthetic metalloproteinase inhibitor potentiates the anti-angiogenic effect of prednisolone in the cornea. Invest Ophthalmol Vis Sci.

117 Davis SD, Sarff LD, Hyndiuk RA. Corticosteroid in experimentally induced Pseudomonas keratitis. Arch Ophthalmol 1978; 96: 126.

118 Smolin G, Okumoto M, Leong-Sit L. Combined gentamicin-tobramycin-corticosteroid treatment II. Effect on gentamicin-resistant Pseudomonas keratitis. Arch Ophthalmol 1980; 98: 473.

119 Badenoch PR, Hay GJ, McDonnell PJ et al. A rat model of bacterial keratitis. Effect of antibiotics and corticosteroids. Arch Ophthalmol 1985; 103: 718.

120 Leibowitz HM, Kupferman A. Topically administered corticosteroids: Effect on antibiotic treated bacterial keratitis. Arch Ophthalmol 1980; 98: 1237.

121 Bohigian GM, Foster CS. Treatment of Pseudomonas keratitis in a rabbit with antibiotic steroid combination. Invest Ophthalmol Vis Sci 1977; 16: 553.

122 Harbin T. Recurrence of corneal Pseudomonas infection after topical steroid therapy. Am J Ophthalmol 1964; 58: 670.

123 Burns RP. Pseudomonas aeruginosa keratitis: mixed infections of the eye. Am J Ophthalmol 1969; 67: 257.

124 Stern GA, Buttross M. Use of corticosteroids in combination with antimicrobial drugs in the treatment of infectious corneal disease. Ophthalmology 1991; 98: 847.

125 Alpren TVP, Hyndiuk RA, Davis SD et al. Cryotherapy for experimental Pseudomonas keratitis. Arch Ophthalmol 1979; 97: 711.

126 Codere F, Brownstein S, Jackson B. Pseudomonas aeruginosa scleritis. Am J Ophthalmol 1981; 91: 706.

127 Eiferman RA. Cryotherapy of Pseudomonas keratitis and scleritis. Arch Ophthalmol 1979; 97: 1637

128 Nassaralla BA, Wang XW, Wee WR et al. Effect of diclofenac sodium on antibiotic treatment of experimental Pseudomonas keratitis. Invest Ophthalmol Vis Sci 1994; 36(4): 4721.

129 Gritz DZ, Kwitko S, Trousdale MD et al. Recurrence of microbial keratitis concomitant with anti-inflammatory treatment in an animal model. Cornea 1992; 11(5): 404.

130 Eiferman RA, Snyder JW. Antibacterial effect of cyanoacrylate glue. Arch Ophthalmol 1983; 101: 958. 
131 Cavanaugh TB, Gottsch JD. Infectious keratitis in cyanoacrylate adhesive. Am J Ophthalmol 1991; 111(4): 466

132 Gottsch JD, Gilbert ML, Goodman DF et al. Excimer laser ablative treatment of microbial keratitis. Ophthalmology 1991; 98(2): 146.

133 Serdarevic $\mathrm{O}$ et al. Excimer laser therapy for experimental Candida keratitis. Am J Ophthalmol 1985; 99: 534.

134 Sarno EM et al. Carbon dioxide laser therapy of Pseudomonas aeruginosa keratitis. Am J Ophthalmol 1984; 97: 791.

135 Kirkness CM, Ficker LA, Steele AD, Rice NS. The role of penetrating keratoplasty in the management of microbial keratitis. Eye 1991; 5(4): 425.

136 Killingsworth DW, Stern GA, Driebe WT et al. Results of therapeutic penetrating keratoplasty. Ophthalmology 1993; 100(4): 534

137 Lotti R, Dart JK. Cataract as a complication of severe microbial keratitis. Eye 1992; 6(4): 400.

138 Moxon R, Rappuoli R. Bacterial pathogen genomics and vaccines. Br Med Bull 2002; 62(1): 45-58.

139 Chalker A, Lunsford R. Rational identification of new antibacterial drug targets that are essential for viability using a genomics-based approach. Pharmacol Ther 2002; 95(1): 1 .

140 Di Guilmi AM, Dessen A. New approaches towards the identification of antibiotic and vaccine targets in
Streptococcus pneumoniae. EMBO Rep 2002; 3(8):

728-734.

141 Waterman SR. Bacterial genomics as a potential tool for discovering new antimicrobial agents. Am J

Pharmacogenomics 2001; 1(4): 263-269.

142 Buchanan SG, Sauder JM, Harris T. The promise of structural genomics in the discovery of new antimicrobial agents. Curr Pharm Des 2002; 8(13): 1173-1188.

143 Dougherty TJ, Barrett JF, Pucci MJ. Microbial genomics and novel antibiotic discovery: new technology to search for new drugs. Curr Pharm Des 2002; 8(13): 1119-1135.

144 Haney SA, Alksne LE, Dunman PM, Murphy E, Projan SJ. Genomics in anti-infective drug discovery getting to endgame. Curr Pharm Des 2002; 8(13): 1099-1118.

145 Klade CS. Proteomics approaches towards antigen discovery and vaccine development. Curr Opin Mol Ther 2002; 4(3): 216-223.

146 Nilsson CL. Bacterial proteomics and vaccine development. Am J Pharmacogenomics 2002; 2(1): 59-65.

147 Huang SH, Triche T, Jong AY. Infectomics: genomics and proteomics of microbial infections. Funct Integr Genomics 2002; 1(6): 331-344.

148 Fernandes PB. The ATCG of drug discovery. Curr Opin Mol Ther 2000; 2(6): 624-632

149 Searls DB. Using bioinformatics in gene and drug discovery. Drug Discov Today 2000; 5(4): 135-143. 